Sociedades Precapitalistas, vol. 8, $\mathrm{n}^{\circ}$ 1, e031, diciembre 2018. ISSN 2250-5121 Universidad Nacional de La Plata.

Facultad de Humanidades y Ciencias de la Educación.

Centro de Estudios de Sociedades Precapitalistas (CESP)

\title{
La democracia ateniense entre la estabilidad y la anarquía
}

\section{Diego Paiaro}

Universidad Nacional de General Sarmiento / Universidad de Buenos Aires /

Programa PEFSCEA / Instituto de Historia Antigua y Medieval "Prof. José

Luis Romero" (FFyL-UBA), CONICET, Argentina

diegopaiaro@ hotmail.com

Cita sugerida: Paiaro, D. (2018). La democracia ateniense entre la estabilidad y la anarquía.

Sociedades Precapitalistas, 8(1), e031. https://doi.org/10.24215/22505121e031

Recibido: 28 agosto 2018 - Aceptado: 02 noviembre 2018 - Publicado: 07 diciembre 2018

(c) (i)(-) (2) Esta obra está bajo licencia Creative Commons Atribución-NoComercial-CompartirIgual 4.0 Internacional c) $\mathrm{http}: / /$ creativecommons.org/licenses/by-nc-sa/4.0/deed.es_AR 


\section{La democracia ateniense entre la estabilidad y la anarquía}

\section{Athenian democracy between stability and anarchy}

Diego Paiaro

Universidad Nacional de General Sarmiento / Universidad

de Buenos Aires / Programa PEFSCEA / Instituto

de Historia Antigua y Medieval "Prof. José Luis

Romero" (FFyL-UBA), CONICET, Argentina

diegopaiaro@hotmail.com

\section{Resumen:}

En un breve artículo sobre las particularidades del gobierno en la Atenas democrática, P.J. Rhodes planteaba que si bien la demokratía no se comportó en el registro histórico-concreto como un sistema anárquico, sin embargo, "el potencial para la anarquía estuvo siempre presente alli'". Teniendo en mente lo anterior, se propone una indagación sobre las condiciones del funcionamiento democrático en la Atenas clásica. En particular, se hace foco en la cuestión de cómo la compulsión al mantenimiento de la isonomía y el poder del dêmos delimitaba las capacidades y posibilidades de acción tanto de los líderes políticos como de los magistrados de la pólis. Como hipótesis se postula que una parte importante de los inconvenientes epistemológicos que la historiografía actual encuentra al momento de asir la democracia ateniense surgen por la tradición de pensar la pólis griega bajo el paradigma de la estatalidad.

Palabras Clave: Atenas, Democracia , Anarquía, Estado, Estabilidad.

\section{ABSTRACT:}

In a short paper on the particularities of the Athenian democratic government, P.J. Rhodes stated that even though the demokratia does not seems to have been an anarchic system in the historical record, however "the potential for anarchy was always there". Taking that into account, the conditions under which the democracy functioned in classical Athens are analyzed. In particular, the focus is centered on how the compulsion to maintain the isonomia and the power of the demos delimited the capacities and possibilities of action of the political leaders and the magistrates of the polis. As a general hypothesis, it is postulated that one of the main epistemological inconvenient of modern historiography on Athenian democracy is related with the tradition of thinking about the Greek polis under the stateness paradigm.

KeYwords: Athens, Democracy, Anarchy, State, Stability.

\section{ATENAS, LA SOLIDEZ Y LA ANARQUía}

El panorama actual de los estudios especializados sobre la historia ateniense se encuentra, de alguna manera, escindido en su caracterización del régimen político democrático ${ }^{1}$. Por un lado, resulta casi un lugar común para la historiografía proponer que la democracia fue un sistema político extremadamente estable que solamente encontró, entre su nacimiento ${ }^{2}$ durante la primera mitad del siglo $\mathrm{V}$ y su abolición definitiva en el año 322, dos breves interrupciones en los golpes oligárquicos del 411 y el 404. Así, en una postura que podemos caracterizar como paradigmática, M.I. Finley postulaba que "Atenas pudo, por casi doscientos años, encontrar la manera de ser el estado más próspero, poderoso, estable, de mayor paz interior, y culturalmente -por mucho- más rico de todo el mundo griego" (Finley, 1973, p. 23) ${ }^{3}$. Sin embargo, por otro lado, como reconoce el editor de una reciente compilación sobre la estabilidad y la crisis en la democracia ateniense, últimamente ha ganado cierta difusión la idea de que dicha forma institucional habría sido bastante propensa a la anarquía, a la fragmentación y que se trataría, en definitiva, de un sistema carente de estabilidad (Herman, 2011). 
En cierta medida, esta doble percepción de la democracia ateniense como régimen estable o anárquico o estable pero potencialmente anárquico- se encuentra presente de modo más o menos inconsciente en una buena parte de la producción historiográfica especializada. Por ejemplo, cuando de Romilly (1977, p. 93) analizaba las particularidades del concepto bajo el cual los griegos designaron ese régimen político, afirmaba que "en el sentido estricto del término, el régimen democrático, opuesto a la mon-arquía y a la olig-arquia, es una especie de an-arquía. Todos ejercen la soberanía -es decir, nadie lo hace-. O, mejor dicho, la soberanía está encarnada en la ley; y la menor desobediencia a las leyes abre la puerta a la anarquía". La helenista completaba esa apreciación destacando que los griegos sólo pudieron percibir ese "riesgo" de anarquía de forma "lenta y progresiva". En síntesis, la anarquía estaba presente en la propia democracia, solo hacía falta que alguien la pudiera "notar" o le "abriera la puerta". En un sentido de alguna manera concordante, en un breve artículo de P.J. Rhodes en el que se indagaba cuál era el fundamento del poder en la Atenas democrática, el autor planteaba, hacia las conclusiones, que si bien la demokratía, en virtud del consenso existente, no se comportó en la práctica como un sistema anárquico, sin embargo, "el potencial para la anarquía estuvo siempre presente alli" (Rhodes, 2000, p. 474-5).

Esta ambigüedad puede rastrearse incluso entre quienes, en apariencia, son partidarios de la idea de que la democracia fue un régimen sólido. En efecto, aquellos estudiosos que han intentado dar cuenta de la estabilidad ateniense, generalmente lo han hecho proponiendo como factores explicativos elementos que son, fundamentalmente, externos al propio sistema político, a su politeía, y al modo de funcionamiento de la política democrática. De este modo, lo que aseguraría la subsistencia de un régimen que igualaba en el plano político de la ciudadanía a sujetos que eran socioeconómicamente desiguales serían alternativamente o de modo combinado los elementos que detallamos a continuación (al respecto, ver el análisis de Ober, 1989, p. 17-35). En primer lugar, la arkhé ateniense y los beneficios económicos provenientes de la Liga habrían permitido tanto financiar la participación política de los ciudadanos más pobres a través del llamado "misthós político" (es decir, el salario que la ciudad pagaba a los ciudadanos a cambio de su actividad política) como ofrecer a los ricos la posibilidad de enriquecerse con la política imperialista (Finley, 2000, p. 60-84 y 103-23; 1986a, p. 29-31; de Ste. Croix, 1954/5; 1988, p. 341-2; cf. Ober, 1989, p. 23-4; Plácido, 1995; 1997, p. 11-26). En segundo lugar, las contribuciones económicas que la ciudad exigía (aunque en algunos casos se trataba de erogaciones voluntarias) al estrato más acaudalado de la ciudadanía como las liturgias (gymnasiarkhía, khoregía, trierakhía, etc.), los tributos excepcionales de guerra (eisphorá) y las distintas multas, resultaban favorables a la estabilización en tanto que, por un lado, suplían diferentes necesidades financieras de la ciudad pero también, por otro lado, evitaban las acumulaciones excesivas de riqueza (Finley, 1986b, p. 183-6; cf. Ober, 1989, p. 30-1 y 199-202) a la vez que generaban los diferentes mecanismos de redistribución de bienes a través de los cuales la democracia intentaba atenuar las diferencias sociales (cf. Gschnitzer, 1987, p. 190-8; Ober, 1989, p. 199-202 y 240-7; Mossé, 1962, p. 305-9; 1995, p. 85-120; 2007, p. 78-83; Sancho Rocher, 1997, p. 200-8; de Ste. Croix, 1953; Osborne, 1985, p. 52-53; MacDowell, 1986, p. 161-4; Fuks, 1979/80; Plácido, 2006). En tercer lugar, algunos autores han propuesto que el desarrollo de la esclavitudmercancía habría cumplido un papel esencial en tanto permitiría liberar a los ciudadanos (varones) de las tareas productivas (y reproductivas) necesarias para la subsistencia dándoles la posibilidad de gozar del ocio indispensable para participar de la política y la guerra (Jameson, 1977/8; 1994; 2003; de Ste. Croix, 1988, p. 169-77; Plácido, 1997, p. 151-2; cf. Wood, 1983; 1988; 2000, p. 211-37; 2002; Ober, 1989, p. 24-7) ${ }^{4}$. Por último, otro grupo de autores, de entre los cuales se destaca Ober (1989, p. 205, 240-1 y 304-39), hacen hincapié en la relevancia que los aspectos ideológicos habrían tenido para mantener la cohesión social y política durante la democracia (ver también los trabajos de Meier, 1985, p. 23-31; 1990, p. 140-54 y 157-85; Loraux, 1993; 2007; 2008a; 2008b).

Ahora bien, partiendo de la idea de que las tensiones expresadas en una perspectiva como la enunciada por Rhodes se pueden rastrear en los trabajos de una buena cantidad de especialistas, las preguntas que guían este trabajo son: ¿ por qué, desde una tradición historiográfica muy extendida en el tiempo, se suele 
pensar la democracia ateniense como un sistema que, a pesar de su estabilidad empíricamente constatada, era potencialmente anárquico y carecía de un principio rector capaz de otorgarle un ordenamiento caracterizado por la solidez?; ¿por qué, incluso para algunos antiguos detractores del sistema político vigente en Atenas, la democracia no tenía arkhé, un principio o fundamento ordenador, en tanto se trataba de una politeía ánarkhos, es decir, de una forma constitucional anárquica?

En efecto, de acuerdo con el filósofo Platón, en una democracia cada uno dice lo que le parece y actúa como le da la gana (Pl. R. 557b) en tanto ésta "parece ser una organización política (politeía) agradable (bedeîa), anárquica (ánarkhos) y policroma (poikíle), que distribuye similarmente igualdad (isóteta) tanto a los iguales (isois) como a los desiguales (anisois)" (558c). En tanto, en el análisis que Aristóteles hace en su Politica sobre las causas que generaban la stásis -es decir, las discordias, conflictos, enfrentamientos o, incluso, guerras civiles- el Estagirita (Arist. Pol. 1302b 28-32) planteaba que, en el caso de las democracias, eran los ricos los responsables de desestabilizar las ciudades en tanto despreciaban "la indisciplina y anarquía" (tês ataxias kai anarkhias) que serían propias de los regímenes democráticos y que explicarían la caída de las democracias de Tebas, Mégara, Siracusa y Rodas. A la vez, discutiendo diferentes formas de democracia, Aristóteles asociaba a este régimen político con la "anarquía (anarkhia) de los esclavos... de las mujeres y de los niños" dado que se toleraba el "vivir como uno quiera" y para "la mayoría de los hombres resultaba más agradable vivir desordenadamente (atáktos) que con moderación (sophrónos)” (Arist. Pol. 1319b 25-34) ${ }^{5}$. En síntesis, para el pensamiento antidemocrático, el exceso de libertad, la borradura de las jerarquías sociales y las igualdades que la demokratía instalaba la convertían en un régimen caracterizado por la falta de arkhé, por la anarquía ${ }^{6}$ . Sobre esas fuentes y pensamientos se apoyó durante muchísimo tiempo una larga tradición historiográfica que veía en la demokratía de los atenienses un ejemplo histórico a ser evitado por la potencialidad anárquica de un (irrestricto y carente de controles y límites) "gobierno de la muchedumbre" 7 .

De esta manera, en lo que sigue intentaremos plantear una reflexión acerca de cuáles eran las características de la democracia que determinaron el predominio de esta línea de interpretación según la cual el sistema político vigente en la Atenas clásica, especialmente durante el período de la llamada "democracia radical" (Hignett, 1952, p. 214-51; Davies, 1981, p. 57-67; Jones, 1987; Mossé, 1995, p. 121-3; Musti, 2000, p. $189-248)^{8}$, no fue tan sólido como cabría esperarse en tanto existió, de modo latente, un constante peligro de desestabilización de la pólis, de surgimiento de la stásis y de caída de la ciudad en la anarquía. En base al problema enunciado, propondremos una indagación sobre las condiciones del funcionamiento democrático en la Atenas clásica. En particular, haremos foco en la cuestión de cómo, por un lado, la compulsión a que el poder sea ejercido bajo condiciones igualitarias (isonomía) y, por otro lado, la soberanía del dêmos -que, en gran parte, determinaban la estructura y la dinámica de la ciudad- delimitaron las capacidades y posibilidades de acción tanto de los líderes políticos como de los magistrados de la pólis. En segundo lugar, postularemos como hipótesis que una parte importante de los inconvenientes epistemológicos que la historiografía actual encuentra al momento de asir la democracia ateniense surgen como consecuencia del mantenimiento incuestionado de la tradición de pensar la polis griega bajo el paradigma de la estatalidad.

\section{Politeía democrática E INESTABILIDAD}

La estructura institucional y la forma de funcionamiento de la pólis democrática han sido los elementos fundamentales sobre los que se ha pensado en la potencial inestabilidad de Atenas ${ }^{9}$. Al respecto, dos elementos son de primordial importancia: por un lado, el papel y las características de la ekklesía, es decir, la Asamblea que reunía a todos los ciudadanos, como principal órgano del que emanaban las decisiones políticas más relevantes; por otro, los límites que encontraban quienes practicaban el mando político tanto desde un ámbito institucional en carácter de magistrados como fuera de él en tanto demagogos. 
$\mathrm{Al}$ estar basada en la participación directa de los ciudadanos -y no en un sistema de representación- la democracia requirió del compromiso activo y masivo de los polîtai en el manejo de los asuntos de la ciudad. Tal compromiso se concretaba en la intervención popular en las diversas instancias institucionales de la pólis, en particular -aunque no únicamente- en la Asamblea. La actuación de Efialtes supuso un fuerte impulso de la hegemonía política del dêmos en tanto permitió que se recortaran ciertos poderes del aristocrático Consejo del Areópago, al menos aquéllos que éste habría ganado en los primeros años del siglo V. En el lenguaje de nuestras fuentes, esto supuso que el Areópago dejó de ser "el guardián de la constitución [he tês politeías phylaké]" a la vez que "todas funciones añadidas [ápanta perieîle tà epitheta]" con las que contaba hasta ese entonces fueron repartidas entre la boulé(Consejo de los Quinientos), los dikastéria (Tribunales Populares) y la ekklesia (Asamblea) (Arist. Ath. 25.1-2.) ${ }^{10}$. A partir de ese momento, en consecuencia, el pueblo ateniense ejercerá la soberanía, principalmente, a través de su intervención en la ekklesía que se constituyó en la instancia fundamental para la toma de decisiones (Sinclair, 1999, p. 44-7; Domínguez Monedero \& Pascual González, 1999, p. 138-40; Finley, 1986b, p. 135-6; Rihll, 1995; Gallego, 2003, p. 69; 2018, p. 139-59) ${ }^{11}$.

Su importancia dentro de la politeía y las características de su funcionamiento han hecho de la Asamblea un dispositivo central a partir del cual se pensó en la potencial inestabilidad de Atenas. Si, como ha sido postulado recientemente, la actuación del dêmos en la ekklesía ateniense fue una fuerza instituyente, de carácter mutable, que carecía de anclajes exteriores o superiores a sí misma, entonces, ello implica que se trataba de un dispositivo que portaba la contingencia como su propia naturaleza (Gallego, 2018, p. 139-59; 2011 , p. 181 $)^{12}$. En tanto espacio principal de ejercicio de la soberanía del dêmos, la Asamblea era responsable de sancionar sus decisiones en forma de decretos (pséphisma) que se encontraban, incluso, por encima de las leyes de la pólis (nómos) -al menos hasta las modificaciones introducidas a finales del siglo $\mathrm{V}^{13}-$ lo que para un pensador como Aristóteles suponía que en su presencia "se disuelven todas las magistraturas (katalýntai pâsai hai arkhhai)" (Arist. Pol. 1292a 2-37; cf. Gallego, 2018, p. 57-8). La carencia de controles externos a la propia Asamblea se manifestaba en que ésta no debía rendir cuentas ante nadie (anupeýthunos) a diferencia de lo que pasaba con los magistrados que se encontraban sometidos a la euthýna. En este sentido, las responsabilidades sobre las decisiones tomadas recaían sobre el individuo que había hecho la propuesta y no sobre el pueblo en su conjunto que había votado en un determinado sentido; incluso podía sancionarse al orador que había realizado una propuesta que, una vez votada, resultó, a posteriori, perjudicial para la ciudad (X. Ath. 2.17; cf. Th. 7.14.4).

En cuanto a las condiciones concretas de funcionamiento, éstas también iban en el sentido de evitar los puntos de anclaje haciendo de cada una de las reuniones un evento único y, en gran medida, imprevisible. La isegoría, es decir, el derecho igualitario a la palabra política y la parresía en tanto franqueza o desinhibición en su uso (Roisman, 2004; Balot, 2004; Wallace, 2004; Saxonhouse, 2005; Gallego, 2018, p. 147-8), constituían las precondiciones que enmarcaban el desarrollo de los discursos en la Asamblea en las cuales cualquiera de los presentes podía tomar la palabra ${ }^{14}$, elaborar un discurso y hacer una propuesta para que sea sometida a votación ${ }^{15}$. Asimismo, al estar abierta a todos los ciudadanos, la Asamblea se encontraba sometida a vaivenes circunstanciales en relación a su composición concreta sumando, de este modo, otro elemento de indeterminación al dispositivo. De esta manera, diferentes situaciones coyunturales -tales como el hecho de que los hoplitas se encontrasen en campaña o la flota en una expedición o los pobladores del mundo rural recluidos en la ciudad frente a una invasión del Ática por los ejércitos enemigos, etc.- podían, y de hecho lo hicieron, afectar profundamente el carácter, el desenvolvimiento y los resultados de una determinada reunión asamblearia (Finley, 1986b, p. 101-2). Todo lo anterior suponía la posibilidad cierta de que se generasen mayorías coyunturales, circunstanciales, que podían ser obtenidas con relativa facilidad y que llevaban implícito un alto grado de inestabilidad (Sancho Rocher, 2009b, p. 241-2). Quizás el mejor ejemplo sobre el carácter en cierta manera volátil de la asamblea sea el debate en torno a cómo debían proceder los atenienses respecto de la ciudad de Mitilene. Habiendo decidido una primera ekklesía, a instancias de Cleón, 
matar a todos los mitilenos adultos y vender como esclavos a las mujeres y los niños, una segunda asamblea fue convocada por la ciudad y la decisión previa fue revertida en tanto el pueblo dio su favor, en esa segunda instancia, a la propuesta de Diódoto de perdonar la vida a los mitilenos (Th. 3.36-49). Tal fluidez ha permitido que la lógica bajo la que se gobernaba la democracia ateniense haya sido conceptualizada como una política plebiscitaria impulsada y desarrollada por la Asamblea ${ }^{16}$.

Ahora bien, junto a esta intervención popular canalizada a través de la Asamblea, es un dato de la democracia la notable presencia que en ella desarrollan los líderes políticos. La función de tales sujetos en la política democrática fue de tal importancia que llevó a Finley (1981, p. 31-2), en un estudio ya clásico sobre los "demagogos atenienses", a plantear que el demagogós constituía "un elemento estructural en el sistema político" que resultaba indispensable para su funcionamiento (cf. Sinclair, 1999, p. 76).

Inmediatamente surge, entonces, la pregunta acerca de cómo logró la democracia compatibilizar la isonomía, la soberanía del dêmos y aquella participación política popular de la que hablamos con la existencia de figuras que, reclutadas generalmente entre las familias tradicionales de la aristocracia ${ }^{17}$, ejercieron un rol destacado en la jefatura política. Desde nuestra perspectiva, tal coexistencia fue posible porque la pólis democrática contó de modo deliberado con diferentes herramientas para evitar que aquel liderazgo político pudiera derivar en una escisión del cuerpo cívico que separase y distinguiera de forma estructural y permanente a los gobernantes de los gobernados; o, mejor aún, para evitar que ese liderazgo político se transforme en un poder capaz de ser impuesto sobre el dêmos. Al respecto, Finley (1981, p. 26) postulaba que si fuera necesario escoger una palabra para caracterizar la condición del político en Atenas, esa palabra sería "tensión”. En nuestra lectura, tal situación de "tensión" constituye uno de los resultados de la presencia en la Atenas democrática de diversos mecanismos de control ejercidos por el dêmos que tenían como objetivo principal evitar la concentración del poder en un ciudadano o en un grupo de ellos y se orientaban a la vigilancia de los magistrados, de los líderes políticos y de los sectores ricos de la ciudadanía en general (Finley, 1981, p. 33) ${ }^{18}$.

A lo largo del siglo $\mathrm{V}$ se verifica la presencia de una pluralidad de tales dispositivos que tenían como objeto evitar la concentración del poder y mantener, de ese modo, la isonomía en tanto pilar fundamental del orden democrático. No podemos tratar aquí de modo extenso cada una de estas herramientas entre las que se contaban la rendición de cuentas de los magistrados (Roberts, 1982; Fröhlich, 2004, las multas, las confiscaciones de propiedad, la pérdida de los derechos de ciudadanía (atimía), el exilio, la ejecución y otro tipo de penas, etc. (Sinclair, 1999, p. 237-80 y 291-301; Finley, 1981, p. 33; Rhodes, 1995, p. 157-8). A su vez, especial mención merece el ostracismo en tanto arma en manos del dêmos especialmente creada para custodiar la isonomía, reafirmar el poder del pueblo como sujeto que define quién pertenece a la comunidady, finalmente, evitar el surgimiento de figuras políticas que al concentrar un poder considerado excesivo pongan en riesgo la democracia. No es un dato aleatorio el hecho de que el ostracismo se desarrolle acompañando a la democracia en sus sucesivas etapas de nacimiento, auge y declive durante el siglo $\mathrm{V}^{19}$. Pero estos mecanismos de control no necesariamente consistían solo en procedimientos formalmente institucionalizados ya que existían otros, externos a la politeía, que ayudaban al control sobre los líderes como es el caso de los "rumores públicos" (Larran, 2011), el de la construcción de la figura del héroe trágico en las representaciones teatrales ${ }^{20}$ y el de los llamados "sicofantas", estos últimos, interpretados por Osborne (1990) como un activo dispositivo democrático de regulación política (cf. sin embargo las reservas de Harvey, 1990).

Ahora bien, un breve repaso -que no pretende tratar todos los casos- de la historia de algunos líderes atenienses en el siglo $\mathrm{V}$ puede dejar bien en claro el alcance y la importancia concreta que estos mecanismos adquirieron $^{21}$. En relación a los dirigentes de la época de las guerras con Persia, sabemos que Milcíades, héroe en Maratón, fue condenado a pagar una multa de 50 talentos en 489 luego de que la expedición a Paros que comandaba fracasara (Hdt. 6.136); Temístocles, que tuvo un papel relevante en la batalla de Salamina, sufrió el ostracismo (Plu. Tem. 22.3; cf.Th. 1.135 .3 y los comentarios de Hornblower, 1991, p. 
220) -y luego la muerte (Th. 1.135) - al igual que Arístides y Jantipo aunque estos dos últimos fueron beneficiarios de una amnistía (Arist. Ath. 22.6-7). En cuanto a los líderes de los '70s y '60s, se debe decir que Cimón, hijo de Milcíades y comandante exitoso en una serie de batallas de la temprana Liga Délica, fue condenado al ostracismo en 461 por su política conservadora y de alianza con Esparta (Plu. Cim. 15-17; Per. 9.4). En cuanto a Efialtes, se sabe que fue asesinado aunque no se conocen las circunstancias precisas del caso (Arist. Ath. 25.4). En relación con la época de Pericles, se puede citar a Tucídides, hijo de Melesias y principal opositor a la política periclea, que sufrió el ostracismo en 443 (Plu. Per. 14.2) y el caso del propio Pericles que fue multado y destituido del cargo de strategós cuando su táctica militar se volvió impopular hacia el 430 (Th.2.65). También se podría citar el evento referido únicamente por Antifonte acerca de los hellenotamiai (magistrados encargados de recibir los tributos de la Liga) condenados a muerte erróneamente. Error que fue descubierto cuando ya nueve de los diez integrantes del cuerpo colegiado habían recibido la pena capital (Antipho 5.69-71; cf.Sinclair, 1999, p. 294). Para las últimas décadas del siglo V, tenemos los casos de Pitodoro y Sófocles condenados al exilio y el de Eurimedonte que fue multado luego de regresar de Sicilia con un fracaso en 424 (Th. 4.65). A la vez se podrían citar los casos del historiador Tucídides, exiliado luego de la pérdida de Anfiópolis (Th. 5.26), y el ostracismo de Hipérbolo en 416 (Plu. Nic. 11; Alc. 13; Arist. 7.3-4; Th. 8.73.3.; Theopomp.Hist. FGrH 115 F 96 (b); Androt. FGrH 324 F 42; Pl.Com. fr. 203KasselAustin) ${ }^{22}$. La lista podría seguir con Alcibíades quien partió al exilio voluntario en dos ocasiones para evitar procesos judiciales en 415 -en los que fue condenado a muerte en ausencia y sus propiedades resultaron confiscadas (Th. 6.27-9, 53, 60)- y en 407 (Th. 6.15, 61; X. HG. 1.5.11-7; Plu. Alc. 20-2, 35-6), o los ocho generales de las Arginusas que en el 406 fueron condenados a la pena capital por no recoger los cuerpos de los caídos en la batalla a pesar de salir victoriosos, pena que fue ejecutada sobre los seis que regresaron a Atenas (X. $H G$ 1.7, 2.3.32; D.S. 13.101.1-4; Pl. Ap. 32b-c;cf. Andrewes, 1974; Sinclair, 1999, p. 294-5; Asmonti, 2006).

\section{LOS LÍMITES DEL PENSAMIENTO ESTATAL}

Ahora bien, una vez presentados los elementos básicos de la Asamblea y del liderazgo político en torno de los cuales se suele pensar en la inestabilidad de la democracia ateniense, es el momento de intentar ofrecer una interpretación alternativa. Desde nuestra perspectiva, aquellos especialistas que conciben la demokratía como un sistema potencialmente anárquico lo hacen en tanto su punto de partida es de modo consciente o inconsciente lo que podríamos denominar como el pensamiento estatal. Se trata, en definitiva, de una concepción que parte de la idea de que la pólis griega (y especialmente la Atenas democrática) fue alguna forma específica de Estado, o bien, por el contrario, no fue un Estado en absoluto. Para los primeros resulta paradójico el hecho de que la democracia ateniense haya carecido de las solideces y los anclajes institucionales que permiten la subsistencia y la reproducción del dispositivo estatal a través del mantenimiento del orden; para los segundos, tales carencias y la inestabilidad consecuente resultan rasgos naturales de las sociedades no estatales en tanto estas serían por definición desprovistas de un orden brindado por las instituciones ${ }^{23}$.

Pero más allá de los debates actuales en torno a la estatalidad de la pólis griega antigua ${ }^{24}$, lo que proponemos es correr el eje de las supuestas carencias de la organización democrática para, de ese modo, intentar aprehender al sistema político ateniense desde su positividad. Desde nuestra perspectiva, creemos que lo que explica la singular configuración institucional en Atenas se relaciona con el hecho de que allí el cuerpo cívico se organizó de una manera en la que "conscientemente" se realizaban esfuerzos para evitar la división entre gobernantes y gobernados, entre individuos que detentaban el poder e individuos que estaban sujetos a dicho poder. De forma análoga a como algunos antropólogos han descripto las "sociedades primitivas" en tanto "sociedades indivisas", creemos que se puede pensar al grupo de los ciudadanos en Atenas durante la democracia como una comunidad indivisa que buscaba evitar que nacieran en su seno las distinciones que habrían fracturado a dicha comunidad en dominantes y dominados; es decir, se trataba 
de una comunidad que buscaba preservar su indivisión en tanto grupo poseedor de derechos políticos ${ }^{25}$. Según nuestra interpretación, la forma de funcionamiento de la Asamblea y las herramientas para controlar el liderazgo político operarían en pos de ese objetivo. En última instancia, esta comunidad indivisa intentaba acercarse al ideal democrático tal como éste era formulado por Aristóteles en cuanto a su segundo elemento definidor: "el no ser gobernado preferentemente por nadie, y si no es posible, sólo serlo por turnos"; según el Estagirita "de esta manera se contribuye a la libertad [tèn eleutherian] fundada en la igualdad [tó ison]" (Arist. Pol. 1317b 10-5). O como lo planteaba el Viejo Oligarca, "el pueblo no quiere ser esclavo, aunque la pólis sea bien gobernada, sino ser libre y mandar [eleútheros eînai kai árkhein]" (X. Ath. 1.8). De lo anterior se desprende que el dêmos era "libre" (eleútheros) solamente a condición de "gobernar" (árkhein) la ciudad, es decir que obturando la posibilidad de que el poder se concentrase en una parte reducida de la ciudadanía -lo que para el pensamiento oligárquico implicaría que "la pólis fuera bien gobernada"-, el pueblo evitó su casi segura esclavización y pérdida de libertad manteniendo el ideal de "no ser gobernado preferentemente por nadie".

En síntesis, entonces, podemos decir que la democracia fue anárquica en el sentido literal de la palabra puesto que funcionaba diluyendo la constitución de cualquier relación de poder que pudiera romper la isonomía que estructuraba al cuerpo cívico en tanto grupo de iguales carente de fisuras. Rancière (1996, p. 30) lo expresa al afirmar que esa "igualdad es simplemente la igualdad de cualquiera con cualquiera, vale decir, en última instancia, la ausencia de arkhé, la pura contingencia de todo orden social". Se trataba, en definitiva, de un sistema organizado intencionadamente para evitar que un ciudadano o un grupo de ellos ejercieran el poder sobre el resto de los polîtai. Sin embargo esto no implicó que, necesariamente, se haya tratado de un régimen inestable; más bien deberíamos decir que la democracia fue estable en su anarquía y, en ese sentido, cumplió, a su modo, con la advertencia de la Atenea imaginada por Esquilo en Las Euménides (A. Eu. 696-7) al evitar tanto el despotismo que supone el poder de un(os) ciudadano(s) sobre otros como la anarquía si la entendemos como falta de solidez del régimen político.

\section{RefERENCiAS}

Andrewes, A. (1974). The Arginousai Trial. Phoenix, 28.1, 112-22.

Asmonti, L.A. (2006). The Arginusae Trial, the Changing Role of Strategoi and the Relationship between Demos and Military Leadership in Late-Fifth Century Athens. Bulletin of the Institute of Classical Studies, 49.1, 1-21.

Balot, R.K. (2004). Free Speech, Courage, and Democratic Deliberation. En I. Sluiter \& R. Rosen (eds.). Free Speech in Classical Antiquity (pp. 233-59). Leiden: Brill.

Blanshard, A.J. (2004). What Counts as the Demos? Some Notes on the Relationship between the Jury and "the People" in Classical Athens. Phoenix, 58.1/2, 28-48.

Brock, R. (1994). The Labour of Women in Classical Athens. The Classical Quarterly, 44.2, 336-46.

Calame, C. (2018). Thésée et l'imaginaire athénien. Légende et culte en Gréce antique. París: La Découverte.

Cammack, D. (2013). Rethinking Athenian Democracy (Tesis doctoral). Cambridge: Harvard University. Recuperado de http://scholar.harvard.edu/files/dlcammack/files/cammack-rethinking_athenian_democracy.pdf

Cammack, D. (2017). Not Talking but Thinking and Voting: Democratic Deliberation in Classical Athens. SSRN's eLibrary. Recuperado de http://dx.doi.org/10.2139/ssrn.2161074.

Cammack, D. (en prensa). Deliberation in Ancient Greek Assemblies. Classical Philology.

Canevaro, M. (2013). Nomothesia in Classical Athens: What Sources Should We Believe? The Classical Quarterly, 63.1, 139-60.

Canevaro, M. (2015). Making and Changing Laws in Ancient Athens. En E.M. Harris \& M. Canevaro (eds.). Oxford Handbook of Ancient Greek Law . Oxford: Oxford University Press. Recuperado de https://dx.doi.org/10.109 3/oxfordhb/9780199599257.013.4 
Canevaro, M. (2017). El imperio de la ley como criterio para la legitimidad política en las ciudades-Estado griegas. Revista Jurídica de Buenos Aires, 42, 159-93.

Canevaro, M. \& Esu, A. (2018). Extreme Democracy and Mixed Constitution in Theory and Practice. Nomophylakia and Fourth-Century Nomothesia in the Aristotelian Athenaion Politeia. En C. Bearzot, M. Canevaro, T. Gargiulo \& E. Poddighe (eds.). Athenaion Politeiai tra storia, politica e sociologia: Aristotele e Pseudo-Senofonte (pp. 105-45). Milán: LED Edizioni Universitarie.

Christ, M.R. (1998). The Litigious Athenian. Baltimore: John Hopkins University Press.

Clastres, P. (2001). Investigaciones en antropología politica. Barcelona: Gedisa.

Clastres, P. (2008). La sociedad contra el Estado. Buenos Aires: Terramar Ediciones.

Cohen, D. (1995). Law, Violence, and Community in Classical Athens. Cambridge: Cambridge University Press.

Connor, W.R. (1992). The New Politicians of Fifth-Century Athens. Cambridge: Hackett Publishing Company.

Davies, J.K. (1981). La democracia y la Grecia clásica. Madrid: Taurus.

de Romilly, J. (1977). Los fundamentos de la democracia. Madrid: CUPSA Editorial.

de Ste. Croix, G.E.M. (1953). Demosthenes TIMHMA and Athenian eisphora in the Fourth Century B.C. Classica et Mediaevalia, 14, 30-70.

de Ste. Croix, G.E.M. (1954/5). The Character of the Athenian Empire. Historia: Zeitschrift für Alte Geschichte, 3.1, $1-41$.

de Ste. Croix, G.E.M. (1988). La lucha de clases en el mundo griego antiguo. Barcelona: Editorial Crítica.

Domínguez Monedero, A. \& Pascual González, J. (1999). Esparta y Atenas en el siglo V a. C. Madrid: Editorial Síntesis.

Eder, W. (1998). Aristocrats and the Coming of Athenian Democracy. En I. Morris \& K.A. Raaflaub (eds.). Democracy 2.500? Questions and Challenges (pp. 106-36). Dubuque: Kendall/Hunt Publishing Company.

Finley, M.I. (1973). Democracy Ancient and Modern. New Brunswick: Rutgers University Press.

Finley, M.I. (1981). Demagogos atenienses. En M.I. Finley (ed.). Estudios sobre historia antigua (pp. 11-36). Madrid: Ediciones Akal.

Finley, M.I. (1983). La Grecia primitiva: edad del Bronce y era arcaica. Barcelona: Editorial Crítica.

Finley, M.I. (1986a). La economía de la antigüedad. México: Fondo de Cultura Económica.

Finley, M.I. (1986b). El nacimiento de la política. Barcelona: Editorial Crítica.

Finley, M.I. (1990). La revolución en la antigüedad. En R. Porter \& M. Teich (eds.). La revolución en la historia (pp. 71-87). Barcelona: Editorial Crítica.

Finley, M.I. (2000). La Grecia antigua. Economia y sociedad. Barcelona: Editorial Crítica.

Forsdyke, S. (2005). Exile, ostracism, and democracy: the politics of expulsion in ancient Greece. Princeton: Princeton University Press.

Foxhall, L. (1989). Household, Gender and Property in Classical Athens. The Classical Quarterly, 39.1, 22-44.

Fröhlich, P. (2004). Les cités grecques et le contrôle des magistrats (IVe - Ier siècle avant J.-C.). Ginebra: Droz.

Fuks, A. (1979/80). Toîs aporouménois koinoneîn: the Sharing of Property by the Rich with the Poor in Greek Theory and Practice. Scripta Classica Israelica, 5, 46-63.

Gallego, J. (2003). La democracia en tiempos de tragedia. Asamblea ateniense y subjetividad politica. Buenos Aires: Miño y Dávila Editores.

Gallego, J. (2011). La asamblea ateniense y el problema del Estado. Instauración y agotamiento de una subjetividad política. En M. Campagno, J. Gallego \& C. García Mac Gaw (eds.). El Estado en el Mediterráneo antiguo. Egipto, Grecia, Roma (pp. 181-222). Buenos Aires: Miño y Dávila.

Gallego, J. (2016). Aristóteles, la democracia ateniense y el problema de la anarquía. El Arco y la Lira. Tensiones y Debates, 4, 29-43.

Gallego, J. (2018). La anarquía de la democracia. Asamblea ateniense y subjetivación del pueblo. Buenos Aires: Miño y Dávila Editores. 
Gallego, J. \& Iriarte, A. (2009). La tragedia ática: política y emotividad. En L. Sancho Rocher (ed.). Filosofía y democracia en la Grecia antigua (pp. 103-26). Zaragoza: Prensas Universitarias de Zaragoza.

Gschnitzer, F. (1987). Historia social de Grecia. Madrid: Ediciones.

Hammer, D. (2002). The Iliad as Politics. The Performance of Political Thought, Norman: University of Oklahoma Press. Hammer, D. (2005). Plebiscitary Politics in Archaic Greece. Historia: Zeitschrift für Alte Geschichte, 54.2, 107-31.

Hansen, M.H. (1974). The Sovereignty of the People's Court in Athens in the Fourth Century BC and the Public Action against Unconstitutional Proposals. Odense: Odense Universitetsforlag.

Hansen, M.H. (1983). The Athenian Ecclesia I. A collection of Articles 1976-83. Copenhague: Museum Tusculanum Press.

Hansen, M.H. (1989). The Athenian Ecclesia II. A Collection of Articles 1983-89. Copenhague: Museum Tusculanum Press.

Hansen, M.H. (1999). The Athenian Democracy in the Age of Demosthenes. Structure, Principles, and Ideology. Norman: University of Oklahoma Press.

Hansen, M.H. (2010). The Concepts of Demos, Ekklesia and Dikasterion in Classical Athens. Greek, Roman and Byzantine Studies, 50, 499-536.

Harris, E.M. (2006). Democracy and the Rule of Law in Classical Athens: Essays on Law, Society and Politics. Cambridge: Cambridge University Press.

Harris, E.M. (2013). The Rule of Law in Action in Democratic Athens. Oxford: Oxford University Press.

Harris, E.M. (2016). From Democracy to the Rule of Law? Constitutional Change in Athens during the Fifth and Fourth Centuries BCE. En C. Tiersch (ed.). Die Athenische Demokratie im 4. Jahrhundert. Zwischen Modernisierung und Tradition (pp. 73-88). Stuttgart: Franz Steiner Verlag.

Harvey, D. (1990). The Sykophant and Sykophancy: Vexatious Redefinition. En P. Cartledge, P. Millett \& S. Todd (eds.). Nomos: Essays in Athenian Law, Politics, and Society (pp. 103-21). Cambridge: Cambridge University Press.

Herman, G. (2006). Morality and Behavior in Democratic Athens. Cambridge: Cambridge University Press.

Herman, G. (2011). Preface. En G. Herman (ed.). Stability and Crisis in Athenian Democracy (pp. 9-10). Stuttgart: Steiner Verlag.

Hignett, C. (1952). A History of the Athenian Constitution to the End of the Fifth Century B.C. Oxford: Oxford University Press.

Hornblower, S. (1991). A Commentary on Thucydides. Volume I. Books I-III. Oxford: Clarendon Press.

Iriarte Goñi, A. (2002). De Amazonas a ciudadanos. Pretexto ginecocrático y patriarcado en la Grecia antigua. Madrid: Ediciones Akal.

Ismard, P. (2014). Le simple corps de la cité Les esclaves publics et la question de l'État grec. Annales. Histoire, Sciences Sociales, 69.3, 723-51.

Ismard, P. (2015). La démocratie contre les experts. Les esclaves publics en Grèce ancienne. París: Seuil.

Jameson, M.H. (1977/8). Agriculture and Slavery in Classical Athens. The Classical Journal, 73.2, 122-45.

Jameson, M.H. (1994). Class in the Ancient Greek Countryside. En P. Doukellis \& L. Mendoni (eds.). Structures rurales et sociétés antiques (pp. 55-63). París: Les Belles Lettres.

Jameson, M.H. (2003). El trabajo agrícola en la Grecia antigua. En J. Gallego (ed.). Elmundo rural en la Grecia antigua (pp. 43-70). Madrid: Ediciones Akal.

Jones, L.A. (1987). The Role of Ephialtes in the Rise of Athenian Democracy. Clasical Antiquity, 6.1, 53-76.

Keyt, D. (1996). Aristotle and the Ancient Roots of Anarchism. Topoi. An International Review of Philosophy, 15.1, $129-42$.

Knox, R. (1985). «So Mischievous a Beaste»? The Athenian Demos and its Treatment of its Politicians. Greece \& Rome, 32.2, 132-61.

Lanni, A. (2006). Law and Justice in the Courts of Classical Athens. Cambridge: Cambridge University Press. 
Lanni, A. (2016). Law and Order in Ancient Athens. Cambridge: Cambridge University Press.

Larran, F. (2011). Le bruit qui vole. Histoire de la rumeur et de la renommée en Grèce ancienne. Toulouse: Presses Universitaires du Mirail..

Lonis, R. (1983). Astu et Polis. Remarques sur le vocabulaire de la ville et de l'État dans les inscriptions attiques du V au milieu du II s. av. J.-C. Ktèma. Civilisations de l'Orient, de la Grèce et de Rome antiques, 8, 95-109.

Loraux, N. (1979). Aux origines de la démocratie. Sur la «transparence» démocratique. Raison Présente, 49, 3-13.

Loraux, N. (1993). L'Invention d'Athènes. Histoire de l'oraison funèbre dans la «cité classique». Paris: Payot.

Loraux, N. (2007). Nacido de la tierra. Mito y política en Atenas. Buenos Aires: El Cuenco de Plata.

Loraux, N. (2008a). La guerra civil en Atenas. La politica entre la sombra y la utopia. Madrid: Ediciones Akal.

Loraux, N. (2008b). La ciudad dividida. El olvido en la memoria de Atenas. Madrid: Katz Editores.

Macdonald, Ch. (2011). Primitive Anarchs: Anarchism and the Anthropological Imagination. Social Evolution \& History, 10.2, 67-86.

MacDowell, D. (1986). The Law in Classical Athens. Nueva York: Cornell University Press.

Mann, Ch. (2007). Die Demagogen und das Volk: Zurpolitischen Kommunikation im Athen des 5 Jahrhundert v. Chr. Berlin: Akademie Verlag.

Meier, Ch. (1985). Introducción a la antropología política de la Antigüedad clásica. México: Fondo de Cultura Económica.

Meier, Ch. (1990). The Greek Discovery of Politics. Cambridge: Harvard University Press.

Mirón Pérez, M. (2000a). El gobierno de la casa en Atenas clásica: género y poder en el oikos. Studia Historica: Historia Antigua, 18, 103-17.

Mirón Pérez, M. (2000b). Las mujeres, la tierra y los animales: naturaleza femenina y cultura política en Grecia antigua. Florentia Iliberritana, 11, 151-69.

Mirón Pérez, M. (2004). Oikos y oikonomia: el análisis de las unidades domésticas de producción y reproducción en el estudio de la economía antigua. Gerión, 22.1, 61-79.

Mossé, C. (1962). La fin de la démocratie athénienne. Aspects sociaux et politiques du déclin de la cité grecque. París: Presses Universitaires de France.

Mossé, C. (1987). Historia de una democracia: Atenas. Madrid: Ediciones Akal.

Mossé, C. (1995). Politique et société en Grèce ancienne. Le «modèle» athénien. París: Aubier.

Mossé, C. (2007). Pericles. El inventor de la democracia. Madrid: Espasa Calpe.

Musti, D. (2000). Demokratía. Origenes de una idea. Madrid: Alianza Editorial.

Ober, J. (1989). Mass and Elite in Democratic Athens. Rhetoric, Ideology and the Power of the People. Princeton: Princeton University Press.

Ober, J. (1996). The Athenian Revolution. Essays on Ancient Greek Democracy and Political Theory. Princeton: Princeton University Press.

Ober, J. (1998). Revolution Matters: Democracy as Demotic Action, Response to Kurt Raaflaub. En I. Morris \& K.A. Raaflaub (eds.). Democracy 2.500? Questions and Challenges (pp. 67-85). Dubuque: Kendall/Hunt Publishing Company.

Ober, J. (2007). «I Besieged that Man». Democracy's Revolutionary Start. En K.A. Raaflaub, J. Ober \& R.W. Wallace (eds.). Origins of Democracy in Ancient Greece (pp. 83-104). Berkeley: University of California Press.

Ober, J. (2015). The Rise and Fall of Classical Greece. Princeton: Princeton University Press.

Osborne, R. (1985). Law in Action in Classical Athens. The Journal of Hellenic Studies, 105, 40-58.

Osborne, R. (1990). Vexatious Litigation in Classical Athens: Sykophancy and the Sycophant. En P. Cartledge, P. Millett \& S. Todd (eds.). Nomos: Essays in Athenian Law, Politics, and Society (pp. 83-102). Cambridge: Cambridge University Press. 
Ostwald, M. (1986). From Popular Sovereignty to the Sovereignty of Law. Law, Society and Politics in Fifth-Century Athens. Berkeley: University of California Press.

Paiaro, D. (2011). Las ambigüedades del Estado en la democracia ateniense. En M. Campagno, J. Gallego \& C. García Mac Gaw (eds.). El Estado en el Mediterráneo antiguo. Egipto, Grecia, Roma (pp. 223-42). Buenos Aires: Miño y Dávila.

Paiaro, D. (2012a). Defendiendo la libertad del dêmos. Control popular y ostracismo en la democracia ateniense. Anales de Historia Antigua y Medieval, 44, 33-62.

Paiaro, D. (2012b). «Ándres gàr pólis». Algunas reflexiones acerca de los debates recientes en torno a la estatalidad de la ciudad griega antigua a la luz del caso ateniense. En E. Dell'Elicine, H. Francisco, P. Miceli \& A. Morin (eds.), Pensar el Estado en las sociedades precapitalistas. Pertenencia, limites y condiciones del concepto de Estado (pp. 51-77). Los Polvorines: Universidad Nacional de General Sarmiento.

Paiaro, D. (2014). Salvajes en la ciudad clásica: Pierre Clastres y la antropología política de la democracia ateniense. En M. Campagno (ed.). Pierre Clastres y las sociedades antiguas (pp. 119-40). Buenos Aires: Miño y Dávila.

Paiaro, D. (2016). El miedo a la tiranía: la protección de la democracia en el régimen político ateniense. En M. Campagno, J. Gallego \& C. García Mac Gaw (comps.). Regimenes políticos en el Mediterráneo Antiguo (pp. 115-27). Buenos Aires: Miño y Dávila.

Paiaro, D. (2018a). Entre el «gobierno de la muchedumbre» y la «dictadura del proletariado». La historiografía de la democracia ateniense frente al espejo de la Revolución. En Á. Moreno Leoni \& A. Moreno (eds.). Historiografía moderna y mundo antiguo (1850-1970) (pp. 93-134). Córdoba: Tinta Libre Ediciones.

Paiaro, D. (2018b). La pólis, el Estado y los ciudadanos de la democracia ateniense como una comunidad indivisa. Mare Nostrum: Estudos sobre o Mediterrâneo Antigo, 9.10, 1-39. Recuperado de https://www.revistas.usp.br/mareno strum/article/view/150386.

Paiaro, D. (2018c). Relaciones, lógicas y prácticas que configuran (o resisten) lo estatal. Mare Nostrum: Estudos sobre o Mediterrâneo Antigo, 9.10, 97-108. Recuperado de http://www.revistas.usp.br/marenostrum/article/view/1 50393.

Paiaro, D. \& Requena, M. (2015). «Muchas veces pegarías a un ateniense creyendo que era un esclavo...» (PS-X, 1, 10): espacios democráticos y relaciones de dependencia en la Atenas Clásica. En A. Beltrán, I. Sastre \& M. Valdés (eds.). Los espacios de la esclavitud y la dependencia desde la Antigüedad. Homenaje a Domingo Plácido. Actas del XXXV coloquio del GIREA. (pp. 153-70). Besançon: Presses Universitaires de Franche-Comté.

Picaso Gurina, M. (2008). Alguien se acordará de nosotras. Mujeres en la ciudad griega antigua. Barcelona: Edicions Bellaterra.

Plácido, D. (1995). Imperialismo y democracia: coherencia y paradoja en la Atenas del siglo V a.C. Anales de Historia Antigua y Medieval, 28, 73-87.

Plácido, D. (1997). La sociedad ateniense. La evolución social en Atenas durante la guerra del Peloponeso. Barcelona: Editorial Crítica.

Plácido, D. (2006). Liturgias, evergetismo y mistoforía: los modos de redistribución de la ciudad democrática. En F. Marco; F. Pina \& J. Remesal, J. (eds.). Repúblicasy ciudadanos: modelos departicipación civica en el mundo antiguo (pp. 41-54). Barcelona: Universitat de Barcelona.

Raaflaub, K.A. (1998a). Power in the Hands of the People: Foundations of Athenian Democracy. En I. Morris \& K.A. Raaflaub (eds.). Democracy 2.500? Questions and Challenges (pp. 31-66). Dubuque: Kendall/Hunt Publishing Company.

Raaflaub, K.A. (1998b). The Thetes and Democracy (A Response to Josiah Ober). En I. Morris \& K.A. Raaflaub (eds.). Democracy 2.500? Questions and Challenges (pp. 87-103). Dubuque: Kendall/Hunt Publishing Company.

Raaflaub, K.A. (2007a). The Breakthrough of Demokratia in Mid-Fifth-Century Athens. En K.A. Raaflaub, J. Ober \& R.W. Wallace (eds.). Origins of Democracy in Ancient Greece (pp. 105-54). Berkeley: University of California Press.

Raaflaub, K.A. (2007b). Introduction. En K.A. Raaflaub, J. Ober \& R.W. Wallace (eds.). Origins of Democracy in Ancient Greece (pp. 1-21). Berkeley: University of California Press. 
Rancière, J. (1996). El desacuerdo. Política y fllosofía. Buenos Aires: Ediciones Nueva Visión.

Requena, M. (en prensa). Imperio de la ley y democracia ateniense. En C. Fernández \& J. Gallego (eds.). Democracia, pasión de multitudes. Configuraciones politicas y representaciones cómicas en la Atenas clásica. Buenos Aires: Miño y Dávila Editores.

Requena, M. \& Paiaro, D. (en prensa). Historiografía y participación política de masas: la «decadencia» de la democracia ateniense en el siglo IV a.C. Revista de Historiografia, 30.

Rhodes, P.J. (1981). A Commentary on the Aristotelian Athenaion Politeia. Oxford: Oxford University Press.

Rhodes, P.J. (1994). The Ostracism of Hyperbolus. En R. Osborne \& S. Hornblower (eds.). Ritual, Finance, Politics. Athenian Democratic Accounts Presented to David Lewis (pp. 85-98). Oxford: Clarendon Press.

Rhodes, P.J. (1995). The «Acephalous» Polis? Historia: Zeitschrift für Alte Geschichte, 44.2, 153-67.

Rhodes, P.J. (2000). Who Ran Democratic Athens? En P. Flensted-Jensen, T. Nielsen \& L. Rubinstein (eds.). Polis \& Politics: Studies in Ancient Greek History. Presented to Mogens Herman Hansen on his Sixtieth Birthday (pp. 465-77). Copenhague: Museum Tusculanum Press.

Rhodes, P.J. (2003). Ancient Democracy and Modern Ideology. Londres: Duckworth.

Rihll, T.H. (1995). Democracy Denied: Why Ephialtes Attacked the Areiopagus. The Journal of Hellenic Studies, 115, 87-98.

Roberts, J.T. (1982). Accountability in Athenian Government. Wisconsin: University of Wisconsin Press.

Roberts, J.T. (1994). Athens on Trial. The Antidemocratic Tradition in Western Thought. Princeton: Princeton University Press.

Robertson Rodríguez, E. (2010). El problema de la democracia radical en la Atenas clásica. Intus-Legere Historia, 4.1, 9-32.

Roisman, J. (2004). Speaker-Audience Interaction in Athens: A Power Struggle. En I. Sluiter \& R. Rosen (eds.). Free Speech in Classical Antiquity (pp. 261-78). Leiden: Brill.

Rosenbloom, D. (2004). Ponêroi vs. Chrêstoi: the Ostracism of Hyperbolos and the Struggle for Hegemony in Athens after the Death of Perikles, I. Transactions of the American Philological Association, 134.1, 323-58.

Ruzé, F. (2003). Eunomia. À la recherche de l'équité. París: De Boccard.

Sancho Rocher, L. (1997). Un proyecto democrático. La politica en la Atenas del siglo V. Zaragoza: Egido.

Sancho Rocher, L. (2005). ¿Qué tipo de democracia? La politeia ateniense entre 403 y 322 a.C.. Studia Historica: Historia Antigua, 23, 177-229.

Sancho Rocher, L. (2009a). Entre tradición y revolución: la fundación de la demokratiá. En L. Sancho Rocher (ed.). Filosofia y democracia en la Grecia antigua (pp. 15-39). Zaragoza: Prensas Universitarias de Zaragoza.

Sancho Rocher, L. (2009b). Teoría moderna y demokratía antigua. En L. Sancho Rocher (ed.). Filosofía y democracia en la Grecia antigua (pp. 129-62). Zaragoza: Prensas Universitarias de Zaragoza.

Sancho Rocher, L. (2009c). ¿Una democracia "perfecta"? Consenso, justicia y demokratía en el discurso politico de Atenas (411-322 a.C.). Zaragoza; Institución «Fernando el Católico».

Sancho Rocher, L. (2011). Comunidad e individuo en la democracia Antigua: Garantías del individuo y espacio privado en la democracia ateniense. En M. Campagno, J. Gallego \& C. García Mac Gaw (eds.). El Estado en el Mediterráneo antiguo. Egipto, Grecia, Roma (pp. 243-66). Buenos Aires: Miño y Dávila.

Sancho Rocher, L. (2018). ¿Es la demokratía semejante a la democracia? Lecturas contemporáneas de la democracia ateniense. Logos: Anales del Seminario de Metafisica, 51, 15-33.

Saxonhouse, A.W. (2005). Free Speech and Democracy in Ancient Athens. Cambridge: Cambridge University Press.

Scheidel, W. (1995). The Most Silent Women of Greece and Rome: Rural Labour and Women's Life in the Ancient World (I). Greece \& Rome, 42.2, 202-17.

Scheidel, W. (1996). The Most Silent Women of Greece and Rome: Rural Labour and Women's Life in the Ancient World (II). Greece \& Rome, 43.1, 1-10. 
Sealey, R. (1987). The Athenian Republic: Democracy Or the Rule of Law? Pennsylvania: The Pennsylvania State University Press.

Sinclair, R.K. (1999). Democracia y participación en Atenas. Madrid: Alianza Editorial.

Starr, C.G. (1990). The Birth of Athenian Democracy: the Assembly in the Fifth Century B.C. Oxford: Oxford University Press.

Strauss, B.S. (1987). Athenian Democracy: Neither Radical, Extreme nor Moderate. Ancient History Bulletin,1.6, $127-9$.

Todd, S.C. (1993). The Shape of Athenian Law. Oxford: Oxford University Press.

Vidal-Naquet, P. (1983). Formas de pensamiento y formas de sociedad en el mundo griego. El cazador negro. Barcelona: Ediciones Península.

Walker, H.J. (1995). Theseus and Athens. Oxford: Oxford University Press.

Wallace, R.W. (1998). Solonian Democracy. En I. Morris \& K.A. Raaflaub (eds.). Democracy 2.500? Questions and Challenges (pp. 11-27). Dubuque: Kendall/Hunt Publishing Company.

Wallace, R.W. (2004). The Power to Speak -and not to Listen- in Ancient Athens. En I. Sluiter \& R. Rosen (eds.). Free Speech in Classical Antiquity (pp. 221-32). Leiden: Brill.

Wallace, R.W. (2007). Revolutions and New Order in Solonian Athens and Archaic Greece. En K.A. Raaflaub, J. Ober \& R.W. Wallace (eds.). Origins of Democracy in Ancient Greece (pp. 49-82). Berkerley: University of California Press.

Wood, E.M. (1983). Agricultural Slavery in Classical Athens. American Journal of Ancient History, 8.1, 1-47.

Wood, E.M. (1988). Peasant-citizen and Slave. The Foundations of Athenian Democracy. Londres: Verso Books.

Wood, E.M. (2000). Democracia contra capitalismo. La renovación del materialismo histórico. México: Siglo Veintiuno Editores.

Wood, E.M. (2002). Landlords and Peasants, Masters and Slaves: Class Relations in Greek and Roman Antiquity. Historical Materialism, 10.3, 17-69.

\section{Notas}

1 Quiero agradecer el trabajo realizado por los evaluadores anónimos que me han permitido corregir algunos errores y mejorar ciertas argumentaciones presentes en la primera versión de este artículo. Todas las fechas que se indican a continuación son a.C. a menos que se indique lo contrario.

2 No resulta necesario para el argumento que intentamos presentar especificar en qué momento exacto surge la democracia ateniense. Las fuentes antiguas y la historiografía moderna han atribuido la paternidad de la demokratía,de forma alternativa, a Solón, Clístenes y Efialtes (junto con las respectivas reformas por ellos impulsadas o a ellos atribuidas); incluso hay quienes llevan la instauración de la democracia a una fecha tardía como el año 403, cf. Eder (1998). A la vez, se debe recordar al Teseo creador de la democracia del mito elaborado en la Atenas del los siglos Vy, particularmente, IV, cf. Walker (1995) y Calame (2018, p. 412-5). Solo a modo de ejemplo del profuso debate historiográfico sobre la cuestión, ver Loraux (1979; 1993, p. 84-5 y 211-6); Finley (1983, p. 144; 1990, p. 79-80); Mossé (1987, p. 28); Wallace (1998, p. 2007); Ober (1996, p. 32-52; 1998, p. 2007); Raallaub (1998a; 1998b; 2007a; 2007b); Rhodes (2003, p. 18-26) y Gallego (2003, p. 67-9).

3 Cf. Sancho Rocher (2009a, p. 39) para quien "prácticamente toda la historiografia" reconoce la estabilidad que el sistema democrático tuvo en Atenas.

4 En relación con esta cuestión no se debe perder de vista el importante papel de las mujeres dentro de la economía y la administración del oîkos como elemento fundamental para comprender las prácticas productivas y reproductivas de las unidades domésticas y la configuración de ese male club (al decir de Vidal-Naquet, 1983, p. 242-3) que constituía la vida política en la pólis. Acerca del trabajo de las mujeres ver, entre muchos otros, los aportes realizados por de Ste. Croix (1988, p. 122-8); Wood (1988, p. 115-20); Foxhall (1989); Brock (1994); Scheidel (1995; 1996); Mirón Pérez (2000a; 2000b; 2004); Picazo Gurina (2008, p. 95-118).

5 Sobre la anarquía y la democracia en el pensamiento de Aristóteles, ver Keyt (1996) y Gallego (2016). De modo ciertamente congruente, Platón planteaba que la libertad excesiva y la extensión de la igualdad propia de las democracias, llevaba al trastrocamiento de todas las jerarquías sociales. Así, la democracia llevaba la anarquía (anarkhian) desde el 
espacio político al espacio doméstico (idias oikias) e incluso hasta los animales salvajes (theriomon): la democracia llevaba a que el padre se iguale al hijo, que el maestro tema y adule al alumno, el adulto al joven, y que el meteco (metoíko) y el extranjero (xénon) se equiparen con el ciudadano (astón), etc. Finalmente, la inversión de las jerarquías se daba hasta tal punto que "el extremo de esta libertad de la multitud (tês eleutherías toû pléthos) se produce cuando en tal ciudad, aquellos que han sido comprados, hombres y mujeres (hoi eoneménoi kai hai eoneménai), no son menos libres (medèn hêppon eleútheroi) que quienes los han adquirido"; en ese mundo trastocado de la demokratía, los hombres y las mujeres disfrutaban análogamente de la igualdad frente a la ley (isonomía) y de la libertad (eleuthería). El paroxismo de esta democracia anárquica se evidenciaba en el hecho de que en ella los caballos y los asnos eran tan libres que atropellan a quienes no se apartaban de su camino (Pl. R. 562d-563c). En Paiaro \& Requena (2015) se analiza cómo el pensamiento antidemocrático concibe los efectos disruptivos del exceso de libertad (y la anarquía que esto conlleva) en el régimen político ateniense en el que, desde el punto de vista crítico de la demokratía, se produce una integración en la igualdad de aquellos que no deberían ser incluidos en la ciudad (esclavos, metecos, extranjeros, pobres, mujeres, etc.). Cf. Gallego (2018, p. 64-5).

6 En Esquilo (A. Eu. 696-7) aparece una concepción algo diferente ya que allí vemos a Atenea, la diosa de la democracia, retomar un planteo expresado previamente por las Erinias (525-6) y aconsejar "a los ciudadanos que respeten con reverencia lo que no constituya ni anarquía (ánarkhon) ni despotismo (despotoúmenon)” en un pasaje en el que se pretende delimitar al régimen político ateniense tanto de la anarquía como de un poder de tipo tiránico; cf. la explicación de Iriarte Goñi (2002, p. 75-7) y Gallego (2003, p. 447; 2018, p. 59-61) quien ve en el pasaje una identificación de la tiranía con la anarquía y el poder despótico y a Atenas como el absoluto contrario a aquella; para de Romilly (1977, p. 99-100) la temática se asocia con el ideal soloniano y con la idea que comenzaba a instalarse según la cual una profundización de la democracia tendía más a la anarquía que al despotismo. El propio Platón (Pl. R. 575a) asocia la tiranía con la anarquía y la falta de ley (anarkhía kai anomía). Cf. Esquilo (A. Ag. 883) utiliza demóthrous anarkhía para hablar de una revuelta popular que derriba al Consejo y anarkhian en el sentido de "falta de gobierno" (A. Supp. 906); de acuerdo con Tucídides (Th. 6.72.4), para Hermócrates la multiplicad de estrategos y órdenes (polyarkhian) habrían llevado a la tropa siracusana a una "indisciplinada anarquía" (axýntakton anarkhian); Heródoto (Hdt. 9.23.2) utiliza el término para hablar de una tropa que carece de mando. Al respecto de la anarquía democrática en las fuentes y en los hechos, ver de Romilly (1977, p. 93-157); cf. Gallego (2018, p. 55-70).

7 Esta perspectiva encuentra una larga tradición en la historiografía moderna sobre la Antigüedad que solía pensar la demokratía como un "gobierno de la muchedumbre" inestable, anárquico, corrupto, que otorgaba libertades en exceso a los pobres carentes de propiedad y preparación, etc. Al respecto, ver Paiaro (2018a) y Requena \& Paiaro (en prensa); cf. Roberts (1994, p. 8-11) y Rhodes (2003, p. 27-33). Sancho Rocher (2011, p. 243-4) lo ha resumido de la siguiente manera: "Una comparación somera entre el estilo de vida ateniense y el lacedemonio ha hecho pensar a la mayor parte de los estudiosos, desde el siglo XVIII, que Esparta representaba el paradigma del paraíso de las virtudes republicanas de la disciplina y el servicio a la patria, mientras Atenas lo era de todo lo contrario, el de la anarquía y el libertinaje”.

8 Sin embargo, Strauss (1987) plantea algunas críticas a la adjetivación de la democracia ateniense como "radical", "extrema" o "moderada" por carecer, según su análisis, de sustento en las fuentes antiguas, cf. Sancho Rocher (2009a, p. 26-7) y Robertson Rodríguez (2010).

9 No es nuestra intención analizar aquí el alcance de los cambios que sufre la democracia ateniense hacia finales del siglo en tanto consideramos que no afectan, en general, a nuestra argumentación. Lo cierto es que en el siglo IV las leyes son fijadas por escrito y se sitúan por encima de las potencialidades de la Asamblea (ver infra n.12). A la vez, en el mencionado siglo parecería haber una aceptación tácita del sistema incluso por aquellos sectores que, a fines del siglo V, habían impulsado la oligarquía, ver Sancho Rocher (2009a, p. 35-9; 2009b, p. 246-51).

10 Cf. los comentarios de Rhodes (1981, p. 309-19). Si bien el texto de Aristóteles no se refiere específicamente a la Asamblea sino que utiliza el término tô démo, se infiere que con esa denominación genérica al cuerpo cívico ateniense se está haciendo alusión a la reunión de los ciudadanos en la Asamblea; ver al respecto las útiles reflexiones de Hansen (1983, p. 161-76).

11 En términos generales, ver la propuesta de Starr (1990, p. 13-31). La Asamblea incluso operará, en última instancia, como la manifestación concreta de la pólis a tal punto que, frecuentemente, el término dêmos -que entre otros significados designaba a los ciudadanos- es asimilado directamente a la Asamblea como hemos visto en la nota anterior; ver al respecto: Lonis (1983, p. 105 n. 83); Ruzé (2003, p. 37-53, especialmente en p. 50-1); Plácido (1997, p. 215); Hansen (1983, p. 130-60; 1989, p. 213-8; 1999, p. 94-124).

12 En el pensamiento aristotélico ello implicaba que las asambleas en las democracias constituían aquello que denominaba como aóristos arkhé, es decir, se trataba de una "magistratura indefinida" cuyos decretos se encontrarían por encima de las leyes; cf. Gallego (2003, p. 163-93; 2018, p. 58-9).

13 Retomando lo planteado más arriba en la n. 9, conviene destacar que existe una importante línea de interpretación según la cual, entre finales del siglo $\mathrm{V}$ y principios del siglo IV, los cambios institucionales y la concordia establecida tras la victoria sobre los Treinta Tiranos por la democracia restaurada habrían tenido como consecuencia una merma en la 
soberanía popular al encontrarse, en el nuevo cuadro institucional, mucho más controladas las decisiones del dêmos en la Asamblea redundando, esto último, en una mayor estabilidad del régimen político. Retomando el planteo de Aristóteles (Arist. Pol., 1292a 2-6) acerca de la existencia de dos tipos de democracia -de acuerdo a si en ella manda la ley (nómos) o la multitud (plêthos)-, Ostwald (1986, p. 497-524) ha conceptualizado estos cambios como el paso "de la soberanía popular a la soberanía de la ley” en tanto el dispositivo asambleario se encontraría en el siglo IV restringido en sus funciones y capacidades políticas y los tribunales tomarían, en consecuencia, el centro de la escena. Ver al respecto las argumentaciones de Hansen (1974; 1983, p. 139-58 y 161-76; 1989, p. 219-57, 213-8; 1999, p. 150-5, 300-4, 321-53; 2010); Sealey (1987); Musti (2000, p. 206-18); Gallego (2003, p. 76-78); Blanshard (2004); Sancho Rocher (2005; 2009c). Cf. sin embargo las posturas de Ober (1989, p. 95-103; 1996, p. 107-22; 2015, p. 232-6) y Mossé (1995: 173-178; 2007: 133-143) que matizan fuertemente la idea de un cambio profundo entre los siglos V y IV. Para una puesta al día del debate centrado en las intervenciones de Hansen y Ober, ver el trabajo de Sancho Rocher (2018). Recientemente, Cammack (2013) ha argumentado que el debate tendió a sobredimensionar el papel de la Asamblea en tanto que, desde su perspectiva, serían los tribunales populares la institución verdaderamente clave en la democracia; por ello ha propuesto caracterizar la ciudad de Atenas como una dikastic democracy desde el siglo $\mathrm{V}$ en adelante. Al respecto, resulta de gran interés el trabajo de Requena (en prensa) que, por un lado, realiza una síntesis de todo el debate y, por otro lado, argumenta en favor de la continuidad del poder de la masa plebeya entre los siglos V y IV en los que se daría conjuntamente la soberanía popular y el imperio de la ley. Sus críticas a la postura de Hansen sobre las limitaciones al poder de la Asamblea en el siglo IV resultan, desde mi perspectiva, sobradamente convincentes. La cuestión acerca del denominado "imperio de la ley" (rule of law) ha sido objeto de un profuso debate durante las últimas décadas agrupando, por un lado, a aquellos que conciben al sistema legal ateniense como basado en el imperio de la ley con una serie clara de normas operativas que funcionaban de forma efectiva -junto a los trabajos ya citados, ver también los de Harris (2006; 2013; 2016); Canevaro (2013; 2015; 2017); Canevaro \& Esu (2018, p. 127-9)- y, por otro lado, a quienes privilegian la consideración de la legitimación, la venganza y los aspectos extra-legales de la justicia -junto a los trabajos de Ober ya citados, ver al respecto los textos de Osborne (1985); Todd (1993); Cohen (1995); Christ (1998); Lanni (2006; 2016)-.

14 La parresía en la Asamblea resulta, sin embargo, valorada de forma crítica en algunas de las fuentes (E. Or. 902-906; Isoc. 7.20).

15 Cf. sin embargo la argumentación de Cammack (2017; en prensa) según la cual el pueblo participaba, fundamentalmente, pensando internamente y votando frente a los oradores que resultarían quienes, mayoritariamente, hacían las propuestas que se sometían a la decisión asamblearia.

16 Nos referimos aquí a la propuesta de Gallego (2011, p. 190-1) quien retoma el modelo de "política plebiscitaria" elaborado por Hammer (2002) para el mundo homérico a pesar de que dicho autor plantea que con el establecimiento de la democracia tal tipo de política habría perdido su volatilidad a favor de la estabilidad que le dieron las estructuras institucionales y las leyes (Hammer 2002, p. 168; 2005, p. 121-6).

17 Esto fue por lo menos así hasta la muerte de Pericles y la aparición en la escena política de lo que Connor (1992) llamó "los nuevos políticos" refiriéndose de tal manera a los líderes de las últimas décadas del siglo V que procedían de sectores sociales más modestos en lo económico y menos prestigiosos en cuanto a lo familiar; cf. Finley (1981, p. 28); Arist. Ath. 28.1 -cf. Rhodes (1981, p. 344-51)-. Algunas de las características de los "nuevos líderes" aparecen enunciadas en: Ar. Eq. 180-222; Eup. 117 (Kock) y Arist. Ath. 28.3-4. Recientemente Mann (2007), partiendo del postulado de Finley acerca del rol estructural de los líderes democráticos, ha realizado una profunda revisión del planteo de Connor desestimando el carácter novedoso de los "nuevos políticos".

18 Algunas cuestiones vinculadas a este punto, y en especial su relación con las características "estatales” y "no estatales" de la pólis, se encuentran trabajadas en Paiaro (2011; 2012a; 2012b; 2014; 2016; 2018b y 2018c).

19 Sobre el ostracismo, y especialmente sobre su desarrollo en paralelo con la afirmación y el declive de la "democracia radical”, ver Paiaro (2012a), con bibliografía. Cf. Forsdyke (2005, p. 79-204) quien llama la atención acerca del carácter ritual del ostracismo y, a la vez, descarta la frecuente relación que establecen los historiadores entre ostracismo y combate a la tiranía.

20 En la tragedia, la figura del tirano funciona como un espejo del oligarca de finales del siglo $\mathrm{V}$ y contrasta con el ideal de ciudadano democrático: Sancho Rocher (2009a, p. 33-4) y Gallego \& Iriarte (2009, p. 106-18).

21 Para la cuestión tratada en este párrafo nos hemos basado en el trabajo de Knox (1985) en donde se encuentra reunida y analizada la evidencia documental así como también la bibliografía pertinente sobre la problemática. Cf. Finley (1973, p. 24); Sinclair (1999, p. 293-5); Herman (2006, p. 226).

22 En particular sobre el ostracismo de Hipérbolo, ver los trabajos de Rhodes (1994; 2000, p. 471); Forsdyke (2005, p. 170-5) y Rosenbloom, D. (2004) en los que se analizan las fuentes pertinentes y la bibliografía existente sobre el tema.

23 Para una valoración del “anarquismo primitivo" desde la perspectiva antropológica ver Macdonald (2011).

24 No podemos repasar aquí el debate sobre la estatalidad o no de la pólis griega, al respecto remitimos a Paiaro (2011: 223-32; 2012b; 2018b; 2018c) en los que se resumen las principales posturas y se analiza la bibliografía reciente sobre la problemática. 
Sociedades Precapitalistas, vol. 8, $\mathrm{n}^{\circ}$ 1, e031, diciembre 2018. ISSN 2250-5121

25 Este punto se encuentra desarrollado extensamente en Paiaro (2018b y 2018c). Nuestra perspectiva es deudora de la antropología política de Clastres $(2001 ; 2008)$. Para un análisis del pensamiento de Clastres y su posible relación con la democracia ateniense, ver Paiaro (2014). Cf. Ismard (2014; 2015, p. 167-202) 